\title{
Stop Plan of Express and Local Train for Regional Rail Transit Line
}

\author{
Qin Luo $\mathbb{D},{ }^{1,2}$ Yufei Hou, ${ }^{2}$ Wei Li $\mathbb{D},{ }^{1,3}$ and Xiongfei Zhang ${ }^{1}$ \\ ${ }^{1}$ College of Urban Traffic and Logistics, Shenzhen Technology University, Lantian Road 3002, Shenzhen, China \\ ${ }^{2}$ Shenzhen Key Laboratory of Urban Rail Transit, Shenzhen University, Nanshan Ave 3688, Shenzhen 518000, China \\ ${ }^{3}$ Key Laboratory of Optoelectronic Devices and Systems of Ministry of Education and Guangdong Province, \\ College of Optoelectronic Engineering, Shenzhen University, Nanshan Ave 3688, Shenzhen, China
}

Correspondence should be addressed to Wei Li; aliweib1@126.com

Received 20 November 2017; Revised 26 April 2018; Accepted 6 May 2018; Published 25 June 2018

Academic Editor: Taku Fujiyama

Copyright (C) 2018 Qin Luo et al. This is an open access article distributed under the Creative Commons Attribution License, which permits unrestricted use, distribution, and reproduction in any medium, provided the original work is properly cited.

\begin{abstract}
The urban rail transit line operating in the express and local train mode can solve the problem of disequilibrium passenger flow and space and meet the rapid arrival demand of long-distance passengers. In this paper, the Logit model is used to analyze the behavior of passengers choosing trains by considering the sensitivity of travel time and travel distance. Then, based on the composition of passenger travel time, an integer programming model for train stop scheme, aimed at minimizing the total passenger travel time, is proposed. Finally, combined with a certain regional rail line in Shenzhen, the plan is solved by genetic algorithm and evaluated through the time benefit, carrying capacity, and energy consumption efficiency. The simulation result shows that although the capacity is reduced by 6 trains, the optimized travel time per person is $10.34 \mathrm{~min}$, and the energy consumption is saved by about $16 \%$, which proves that the proposed model is efficient and feasible.
\end{abstract}

\section{Introduction}

With the continuous expansion of urban scale and the development of urban rail transit network, the round-trip passenger flow between city centers and suburbs grows gradually. As the central city is saturated basically, more and more companies and residential buildings tend to transfer to the suburbs, which further promotes the swelling of the traffic flow. Besides, due to the extension of urban rail transit line, it forms long-distance regional rail transit lines [1]. If the train stops frequently, it will inevitably cause the increase of travel time, thereby reducing the operational efficiency and being not conductive to the efficient development of rail transit. And long-distance commuters want to arrive their destinations as soon as possible and passengers at stations along the route wish to reach the destinations without transfer. Therefore, cities need to use express and local train operating mode to meet the demands for the commuters [2]. On the one hand, from the passenger's point of view, this model can shorten the travel time of commuting passenger flow and improve the passenger service level, but at the same time, it will increase the travel time of some local passengers to a certain extent and affect their travel experience. On the other hand, for operating enterprises, the mode will save the train energy consumption, thereby enhancing operational efficiency, but the system carrying capacity will be reduced. For this reason, how to ensure the stop scheme of express trains reasonably and save the passenger travel time to an extreme is a significant project at present.

In view of the demand for commuters, scholars mainly study the mode of the express and local train and the plan of the full-length and short-run route. Based on the express and local train operation mode, the literature mainly considers the travel demand of passengers. For instance, L. Wang [3] considered the shortest total travel time of the passengers to build up an optimization model. R. Tang [4] constructed a linear programming model with the goal of maximizing passenger satisfaction, which is reducing average passenger waiting time. Hassannayebi E et al. [5] studied the optimal time table of express/local train and built up 
a model in order to reduce the passenger waiting time by using variance and penalty function. Chun $\mathrm{J} \mathrm{H}$ et al. [6] come up with the express/local train mode, which can solve the problem of passenger crowding and train delay with building the model of minimizing the number of serviceable cars. Y Lai et al. [7] took transfer passengers into account and then established an innovative network structure to study the train stop plan. Y. Gao et al. [8] proposed a biobjective programming model to achieve the simultaneous minimization of the energy consumption and the travel time. However, the above literature sources do not consider the travel process comprehensively. In the combination mode, there is a situation that express trains cross through local trains. And this part of time should not be ignored. Therefore, Canca D et al. $[9,10]$ also mainly considered meeting the travel demand of the passenger flow from the passenger angle by adjusting the train schedule including the overtaking factor. However, they ignored the commuting passengers' sensitivity to travel time, whose travel purpose is to arrive the destination quickly. Therefore, D. Di et al. [11, 12] established a passenger pathchoice model to determine the passenger principle in path choice by considering perception difference of time without considering the effect of travel distance.

In the condition of the full-length and short-run route, the recent studies mainly focused on the selection of shortrun route, service level, traffic capacity, and rolling stock [13]. For example, J. Q. Liao [14], respectively, devised the operation scheme in condition of the single route and the fulllength and short-run route aiming at the maximum travel saving time of all passengers. Q. Hu et al. [15] analyzed the section of short-run route from the use of the rolling stock and capacity. However, the operation scheme plan of mixed-routing cannot save the travel time for long-distance passengers and solve the problem of commuting effectively.

To sum up, based on the analysis of the composition of passenger travel time and passenger selection behavior, this paper makes a reasonable stop scheme of express trains aiming to reduce the total travel time to maximize the operational efficiency of express/local train for regional rail transit line.

The remainder of the paper is organized as follows. Section 2 analyzes the passenger flow characteristics and the effect of travel time and carrying capacity in the condition of express and local train operating mode. In Section 3, a stopping plan optimization model of trains based on minimizing the total passenger travel time is established, and then the model is solved by genetic algorithm. In Section 4, an example of a regional line in Shenzhen is provided to optimize the train stop plan by using the model and algorithm above and evaluate it by the travel time, the capacity, and the energy consumption compared with the general plan. The final section draws the conclusions and proposes some issues for future.

\section{Analysis of Passenger Flow Characteristics and Effects}

2.1. Passenger Flow Characteristics. The long-distance regional rail transit line is connected in series with urban areas, suburbs, and satellite towns, and the intercity passenger flow is not only large, but also imbalanced in time direction. During the morning rush, the traffic flow moves from satellite towns or suburbs to the downtown, and at the evening peak, the situation is opposite. Meanwhile, with different levels of development along the rail transit, the passenger volume of boarding, and alighting at stations are also inconsistent, and overall, they show the disproportion of the section flow. Consequently, two types of the fluctuating passenger flow have demands for regional express rails: commuters prefer to take the through train from downtown area to the suburban, while short-distance passengers want to reach any two stations directly.

2.2. Travel Time Cost. Although operating express/local train prolongs the total trip time of passengers who take local train because of overtaking, it saves the time of those passengers who take express train.

2.3. Carrying Capacity. Express and local train scheme will reduce the capacity of lines [16]. In the traditional pattern, the line capacity $n_{r}$ is only related to the minimum headway $I$, and its calculating method is as formula (1). However, the carrying capacity of express/local train takes the deduction coefficient method for calculation and analysis. The deduction coefficient of the express train refers to the number of the local cars deducted from the parallel operation chart because of drawing an express train, and the formula is as (2) [17].

$$
\begin{aligned}
& n_{r}=\frac{3600}{I} \\
& \varepsilon_{e}=1+\left(\frac{t_{d}}{I}\right)-k
\end{aligned}
$$

where $\varepsilon_{e}$ is the deduction coefficient of the express train, $t_{d}$ is the difference of travel time of express/local train, and $k$ means the times which are crossed of slow trains.

2.4. Train Energy Consumption. In daily operation, in addition to the maintenance of infrastructure, the energy consumption during the train operation also accounts for a large proportion [18]. And compared to the normal train mode, where trains stop at all stations, the express train only stops at some stations, so the operating scheme of the express and local train reduces the energy consumption of traction and braking at start and stop, and it can achieve the energy saving and emission reduction. In terms of the operating enterprise, it has great benefit [19]. And the equations of energy consumption calculation and parameters (Table 1) are as follows:

$$
\begin{aligned}
E & =E_{t}+E_{b} \\
E_{t} & =\sum_{m=1}^{f_{1}+f_{2}} \sum_{i=1}^{n}\left(\int_{0}^{l_{t}} F_{t} d l\right) \\
E_{b} & =\sum_{m=1}^{f_{1}+f_{2}} \sum_{i=1}^{n}\left(\int_{0}^{l_{b}} F_{b} d l-E_{r}\right)
\end{aligned}
$$




$$
E_{r}=\sum_{m=1}^{f_{1}+f_{2}} \sum_{i=1}^{n} \sum_{k=m+1}^{f_{1}+f_{2}} x_{m, k} \cdot \int_{0}^{l_{t}} F_{b} d l \cdot \xi \cdot \frac{t_{c}}{t_{b}}
$$

where (3) means the total energy consumption, (4) is the train traction energy consumption, (5) is the energy consumption of train braking, and (6) shows the energy saved in regenerative braking.

\section{Optimization Model and Algorithm}

3.1. Problem Description. First, operating express/local train combination plan is mainly for commuting problem, so this paper chooses the morning peak as the optimization period to study. Second, two kinds of trains own the same technical parameters. Third, although the line is divided into the upstream and downstream direction, the model only discusses the one-way situation where the passenger flow is larger. And then, the regional rail transit line which this paper studies can meet the demand of passenger flow without the situation of passenger retention. The last assumption is that passengers' arriving can all be considered to follow the normal distribution.

3.2. Modeling. Passenger travel time $t$ includes waiting time $t_{w}$ and running time $t_{r}$ like formula (7), in which the total passenger waiting time consists of two parts: the first part is the normal passenger waiting time when the foregoing local train is not overtook, and the second part is the increased passenger waiting time at stations caused by overtaking. And $t_{r}$ includes the interval running time and station dwell time.

$$
t=t_{w}+t_{r} .
$$

3.2.1. Analysis of Passenger Selecting Behavior for Train. The research object is commuting passenger flow with early morning rush hour. Considering that passengers are generally unwilling to transfer, this paper assumes that passengers at most experience one transfer in the same line and same direction. Besides, when OD are both express train stations, passengers will not choose the transfer way from express to local train [20]. Therefore, according to the different nature of origin and destination, all kinds of the travel selection behavior are shown in Table 2 .

The behavior of passengers selecting trains can be analyzed by Logit model like formula (8) [21]. And (9) shows the passenger flow who selects some kind of travel mode [22].

$$
p_{i j}^{(k)}=\frac{\exp \left(-\theta \cdot c_{i j}^{(k)}\right)}{\sum_{k \in S} \exp \left(-\theta \cdot c_{i j}^{(k)}\right)}
$$

where $p_{i j}^{(k)}$ is the passenger ratio choosing the mode $k$ to travel from station $i$ to $j, \theta$ is the passenger expectation variable based on travel impedance which is inversely proportional to the passenger expectation, $c_{i j}^{(k)}$ is the impedance choosing the mode $k$ to travel from station $i$ to $j$, and $S$ is collection of travel modes.

$$
q^{(k)}=q_{i j} \cdot P_{i j}^{(k)}
$$

where $q^{(k)}$ is the passengers choosing mode $k$ to travel and $q_{i j}$ is the passengers flowing from $i$ to $j$.

Passenger travel impedance is mainly affected by both the train running time $t_{y}$ and travel distance $l$, and the combined impedance is determined by the weight of both.

(1) Train Running Time. When passengers travel from local to express station or just the reverse, they need to think about transferring. The principles are as follows.

(1) $t_{\text {(trans) }}>t_{(l)}$, where $t_{\text {(trans) }}$ is the total time of changing trains and $t_{(l)}$ only refers to the time of local train. In addition, the transfer time is as

$$
t_{(\text {trans })}=t_{w}^{1}+t_{r}^{1}+t_{w}^{2}+t_{r}^{2}
$$

where $t_{w}^{1}$ and $t_{r}^{1}$, respectively, represent the waiting time and running time including dwell time of the first train for passenger; $t_{w}^{2}$ and $t_{r}^{2}$, respectively, represent the same meaning for the second train.

(2) When passengers consider taking local train to express, they not only need to take the total time into account, but also need to think of whether the middle has express station to supply to transfer.

(2) Travel Distance. The operation ratio of express and local train can be estimated by the number of passengers whose travel distance is greater than five sections and less than five sections, like the following formula [23]:

$$
p=\frac{\sum_{|i-j|>5} q_{i j}}{\sum_{|i-j| \leq 5} q_{i j}} .
$$

From the above two parts, the combined impedance is as (12) and the flow chart of passengers train-choice behavior is as shown in Figure 1.

$$
c_{i j}^{(k)}=\mu_{1} \cdot t_{y}+\mu_{2} \cdot l
$$

where $\mu_{1}$ and $\mu_{2}$ are the weight of train running time and travel distance, and they depend on the specific situation.

3.2.2. Objective Function. Total travel time $t$ is calculated as formula (13) and the model parameters are listed in Table 3.

$$
\begin{aligned}
t= & \left(\sum_{m=1}^{f_{1}} q_{i j-m}^{(l)}+x_{q} \cdot \sum_{m=1}^{f_{2}} q_{i j-m}^{(e)}\right) \cdot\left(\frac{\mathrm{T}}{2 \cdot\left(c_{1} f_{1}+c_{2} f_{2}\right)}\right. \\
& \left.+\sum_{k=1}^{i-1} c_{1} h_{k} x_{k}+t_{i j}+\sum_{w=i+1}^{j-1}\left(t_{s}+c_{1} x_{w} h_{w}\right)\right) .
\end{aligned}
$$

In conclusion, when the number of stations is $n$, the paper establishes the following objective function to achieve the minimization of the total passenger travel time as follows:

$$
\begin{aligned}
\min Z= & \min \left(\sum_{i=1}^{n-1} \sum_{j=i+1}^{n} t\right) \\
\text { s.t. } & q_{i j-m} \leq \eta_{\max } \cdot a \\
& f_{d} \geq 1 \quad(d=1,2,3) .
\end{aligned}
$$


TABLE 1: Energy consumption model parameters.

\begin{tabular}{lc}
\hline Parameters (unit) & Explanation \\
\hline$E(\mathrm{KJ})$ & The total energy consumption \\
$E_{t}(\mathrm{KJ})$ & The traction energy consumption \\
$E_{b}(\mathrm{KJ})$ & $\begin{array}{c}\text { The braking energy consumption } \\
\text { The regenerating energy }\end{array}$ \\
$E_{r}(\mathrm{KJ})$ & The distance of traction \\
$l_{t}(\mathrm{~m})$ & The net force of traction process \\
$F_{t}(\mathrm{KN})$ & Boolean variable. When the $m^{\text {th }}$ and $k^{\text {th }}$ train are in the same power supply section, \\
$x_{m, k}$ & the value is 1 ; otherwise, the value is 0. \\
$l_{b}(\mathrm{~m})$ & The distance of braking \\
$F_{b}(\mathrm{KN})$ & The net force of braking process \\
$\xi$ & The energy transformation ratio \\
$t_{c}(\mathrm{~s})$ & The overlapping time of the acceleration time of the $m^{t h}$ and the braking time of the \\
$t_{b}(\mathrm{~s})$ & $k^{t h}$.
\end{tabular}

TABLE 2: Passenger selection behavior.

\begin{tabular}{lcr}
\hline OD & Local train station & Express train station \\
\hline Local train station & Local train & Local train \\
& & Local train $\rightarrow$ Express train \\
\hline & Local train & Local train \\
& & Local train $\rightarrow$ Express train \\
& Express train $\rightarrow$ Local train & Express train \\
\hline
\end{tabular}

TABLE 3: Model parameters.

\begin{tabular}{|c|c|}
\hline Parameters (unit) & Explanation \\
\hline$f_{1}($ time $/ \mathrm{h})$ & The operating frequency of the local train \\
\hline$f_{2}($ time $/ \mathrm{h})$ & The operating frequency of the express train \\
\hline$x_{q}$ & Boolean variable. When the $i$ station and $j$ station are both local stations, the value is zero. \\
\hline$q_{i j-m}^{(l)}($ person $)$ & The number of passengers waiting for the $m^{\text {th }}$ train which is the local train \\
\hline$q_{i j-m}^{(e)}($ person $)$ & The number of passengers waiting to the $m^{\text {th }}$ train which is the local train \\
\hline $\mathrm{T}(\min )$ & The length of the optimized period \\
\hline$c_{1} / c_{2}$ & $\begin{array}{l}\text { Boolean variable. When passengers take the local train, the value of } c_{1} \text { is one, } c_{2} \text { is zero, and when passengers } \\
\text { take the express train, the value of } c_{1} \text { is zero, } c_{2} \text { is one. }\end{array}$ \\
\hline$h_{k}(\min )$ & The increased delay time because the slow train is crossed by the express train at preceding stations \\
\hline$x_{k}$ & $\begin{array}{c}\text { Boolean variable. When the slow train is crossed by the express train at the } k^{\text {th }} \text { station, the value is one; } \\
\text { otherwise, the value is zero. }\end{array}$ \\
\hline$t_{i j}(\min )$ & The interval running time of trains \\
\hline$t_{s}(\min )$ & The dwelling time at stations \\
\hline$x_{w}$ & $\begin{array}{l}\text { Boolean variable. When the local train is crossed by the express train at the } w^{\text {th }} \text { station, the value is one; } \\
\text { otherwise, the value is zero. }\end{array}$ \\
\hline$h_{w}(\min )$ & The increased dwell time in the trains because the local train is crossed by the express train at this station \\
\hline$q_{i j-m}(\min )$ & The number of passengers waiting for the $m^{\text {th }}$ train \\
\hline$\eta_{\max }$ & Maximum section load factor \\
\hline$a$ & Passenger capacity of the train \\
\hline
\end{tabular}




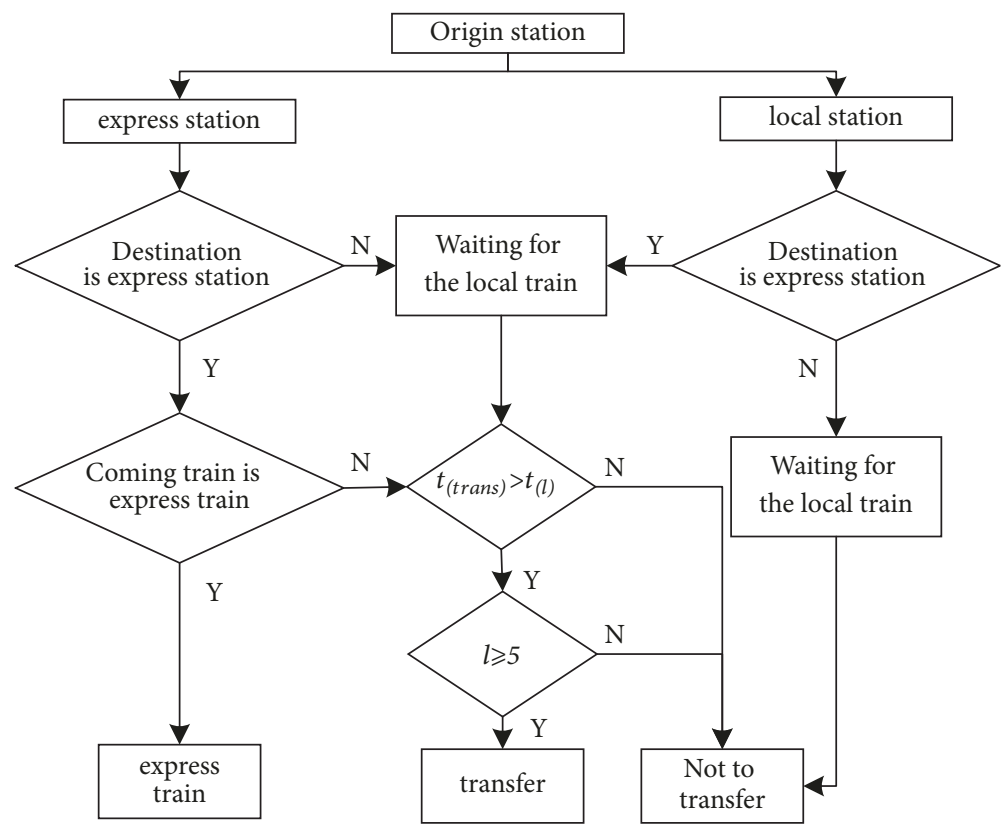

FIGURE 1: The flow chart of passenger train-choice behavior.

3.3. Solution Algorithm. The evolutionary algorithm, which is represented by genetic algorithm, uses crossover and mutation operator to realize the information exchange and local search between individuals in the group and provides each individual with the opportunity of optimization [24]. Through the competitive selection mechanism of survival of the fittest, the evolutionary algorithm guides the population to the better. Exactly, the unique binary coding rule of genetic algorithm is suitable for the value of $0-1$ of the train stop strategy. Besides, instead of starting from a point and optimizing according to a fixed route, it searches the whole feasible solution space at the same time, so it can avoid falling into a local optimum and find the global optimal results. The steps are as follows.

(1) Population initialization. It generates $N$ binary coded individuals randomly, and the length is the number of stations, where in code, 1 means that express train will stop at the corresponding station and 0 means no stopping. What is more, because the express train must stop at the original and terminal stations, the encoding is 1 .

(2) Ensuring the fitness function. It constructs the fitness function as formula (15). The greater the fitness value, the better the individual.

$$
u(x)=M-f(x)
$$

where $M$ means the total time of general mode and $f(x)$ is the time of combination mode with every plan.

(3) Taking the operations of selecting, crossover, and mutation. The selection operation adopts roulette method, the crossover operator is uniform crossover, and the mutation operator is a single point mutation.

(4) After an iteration, the worst individual is replaced by the best individual in the current generation, that is also called "survival of the fittest".

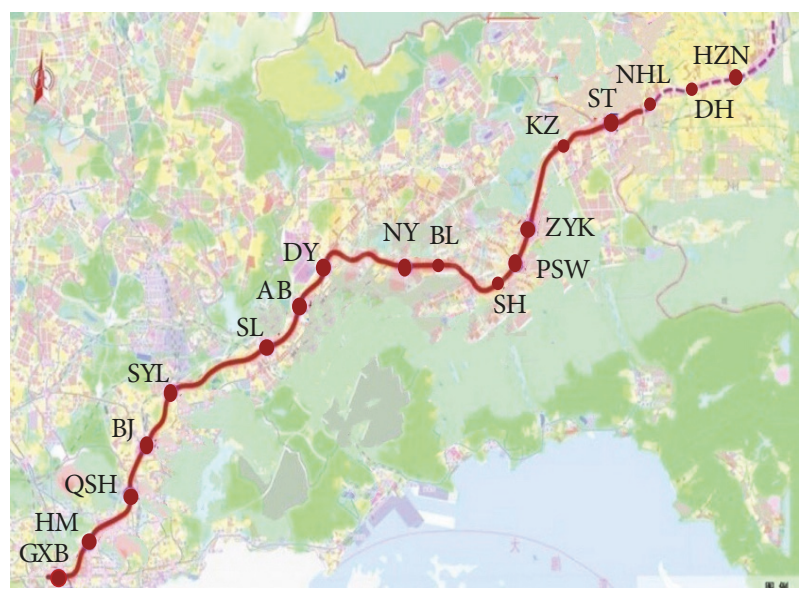

FIGURE 2: The regional rail transit line in Shenzhen.

(5) With the requirement of iterations, steps 4 and 5 are repeated.

\section{Case Analysis}

4.1. Line Profile. Taking a certain line in Shenzhen as an example (Figure 2), this paper analyzes and verifies the optimization of the express and local train stop problem. The data required in the example analysis is shown in Table 4, the OD passenger flow during the morning peak (8:00 9:00) is shown in Table 5 , and the length of interval and pure runtime of trains are followed in Table 6. Besides, according to the OD data, the passenger flow of boarding and alighting and the distribution of section flow of up direction $(\mathrm{GXB} \rightarrow \mathrm{HZN}$ ) and down direction $(\mathrm{HZN} \rightarrow \mathrm{GXB})$ are, respectively, shown in Figures 3, 4, and 5. 
TABLE 4: Values of case parameters.

\begin{tabular}{lccc}
\hline Parameters (unit) & Value & Parameters (unit) & Value \\
\hline Length $(\mathrm{km})$ & 53.07 & Train composition & A8 \\
The number of stations & 18 & Dwell time $(\mathrm{s})$ & 30 \\
Minimum headway $(\mathrm{s})$ & 120 & Maximum running time $(\mathrm{km} / \mathrm{h})$ & 120 \\
Passenger capacity (person) & 2480 & Maximum section load factor & $100 \%$ \\
Passenger expectation variable $\theta$ & 0.9 & Weight $\mu_{1}$ & 0.6 \\
Weight $\mu_{2}$ & 0.4 & & \\
\hline
\end{tabular}

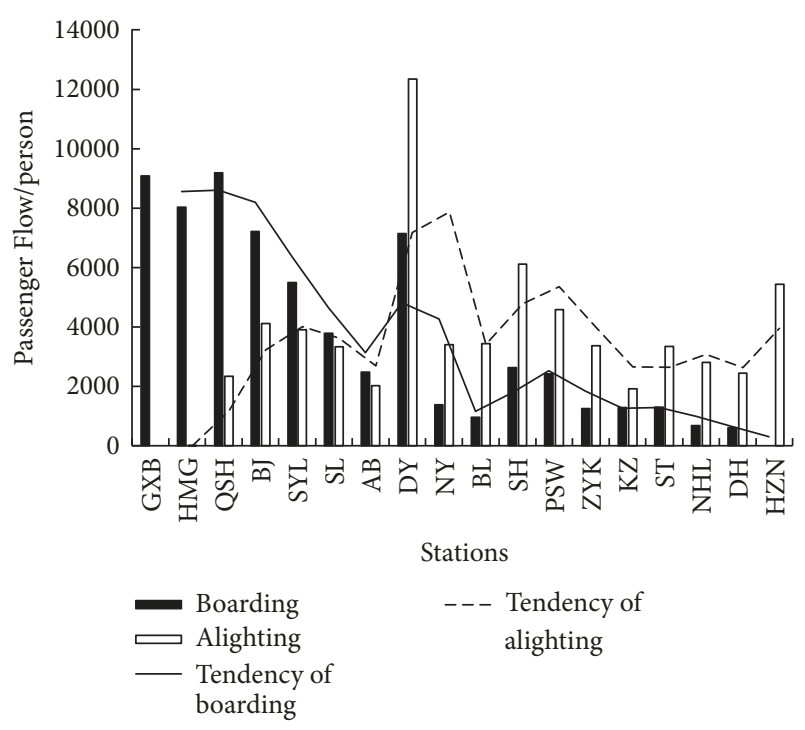

FIGURE 3: The passenger flow of boarding and alighting of up direction.

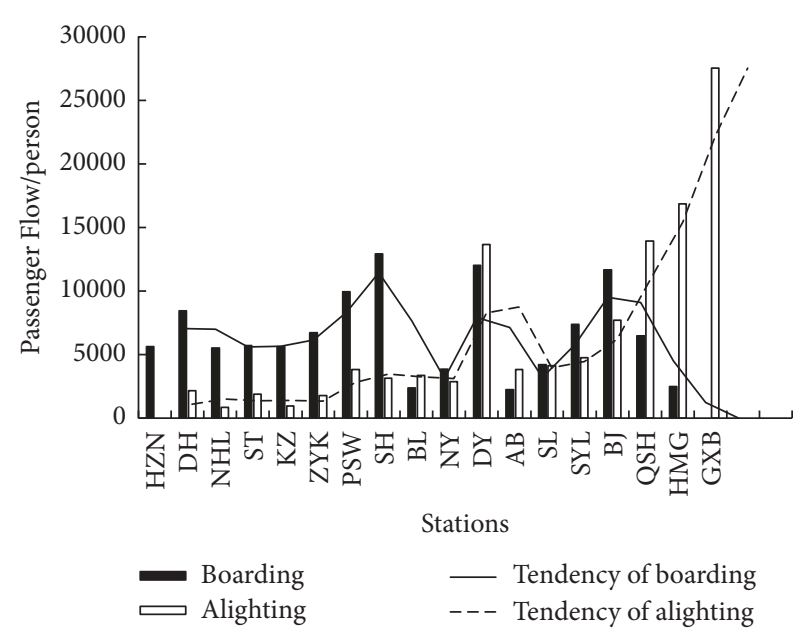

FIGURE 4: The passenger flow of boarding and alighting of down direction.

4.2. Solution. This paper uses the genetic algorithm to solve the model. Different parameters will affect the speed and results of the algorithm. The paper uses two of the population sizes, crossover probability and mutation probability, as the independent variables and the other two as the dependent variables to analyze the influence of the values on algorithm

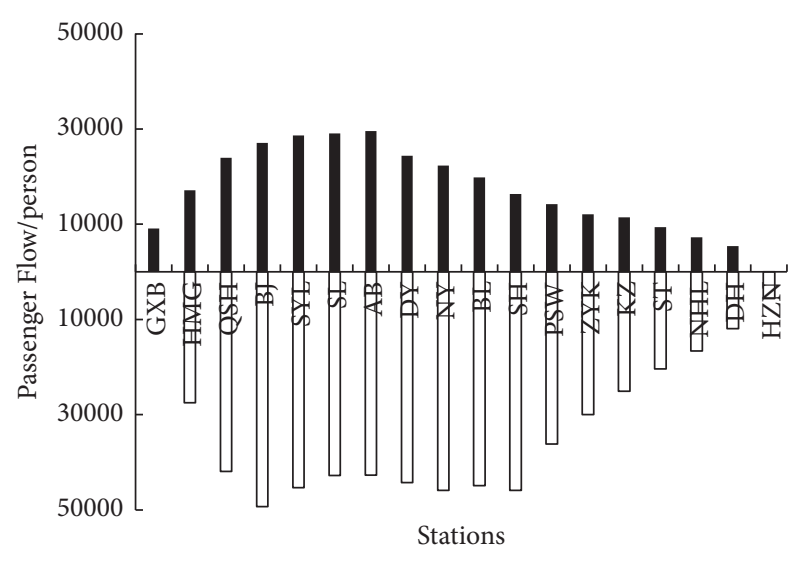

- Up section flow

$\square$ Down section flow

Figure 5: The distribution of section passenger flow.

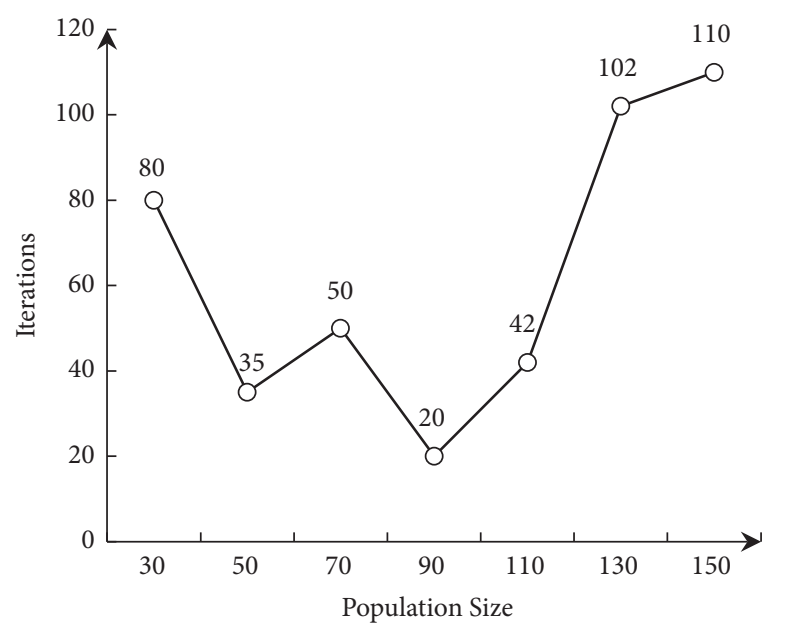

FIGURE 6: The relationship between the population size and number of iterations.

results. When the values of the population size were from 30 to 150 , the results showed that the final fitness value did not change with the population size, while the rate of convergence will be affected as shown in Figure 6. And according to the current literature that the range of the crossover rate is 0.4 to 0.99 and 0.001 to 0.1 , respectively [25], the paper supposes that the crossover rate steps and the mutation rate steps are 0.5 and 0.005 . The results show that although the number of 


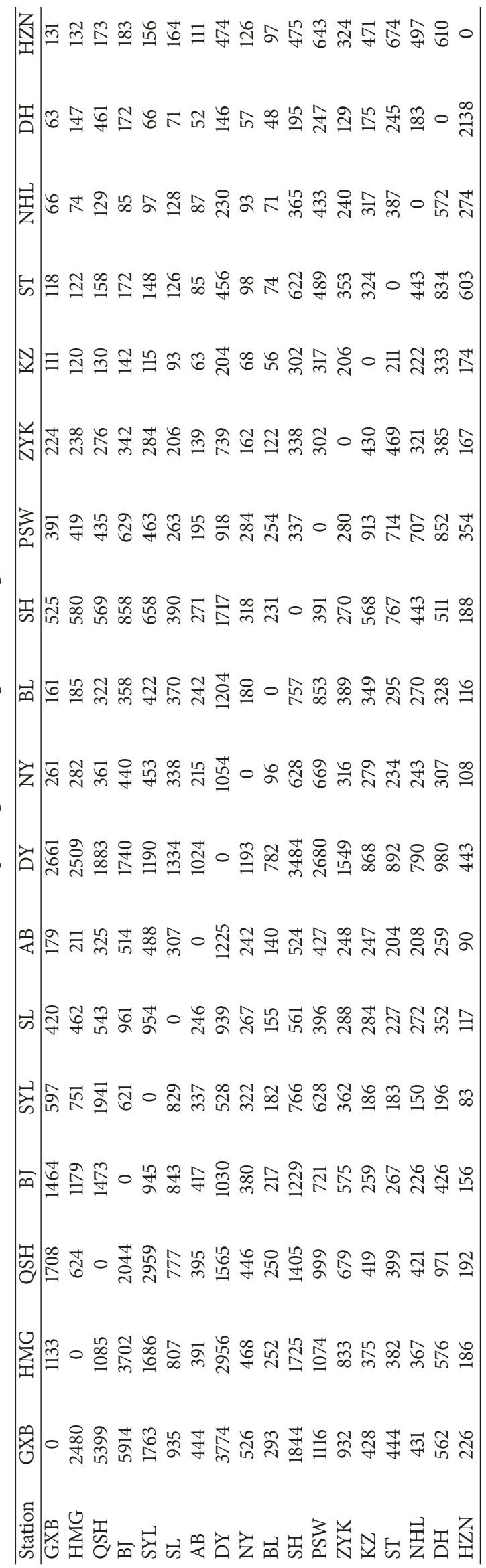


TABLE 6: The length of interval and pure runtime of trains.

\begin{tabular}{|c|c|c|c|c|c|}
\hline Interval & Length $(\mathrm{km})$ & Runtime (min) & Interval & Length $(\mathrm{km})$ & Runtime (min) \\
\hline GXB-HMG & 2.905 & 2.563 & BL-SH & 4.213 & 2.922 \\
\hline HMG-QSH & 4.279 & 3.363 & SH-PSW & 1.566 & 1.521 \\
\hline GSH-BJ & 2.494 & 2.113 & PSW-ZYK & 2.007 & 1.714 \\
\hline BJ-SYL & 3.535 & 2.84 & ZYK-KZ & 4.926 & 3.339 \\
\hline SYL-SL & 6.364 & 4.173 & KZ-ST & 3.229 & 2.367 \\
\hline SL-AB & 3.428 & 2.503 & ST-NHL & 1.623 & 1.634 \\
\hline AB-DY & 2.413 & 1.915 & NHL-DH & 1.745 & 1.795 \\
\hline DY-NY & 6.037 & 4.35 & DH-HZN & 1.238 & 1.241 \\
\hline NY-BL & 2.072 & 1.756 & & & \\
\hline
\end{tabular}

TABLE 7: Values of algorithm parameters

\begin{tabular}{lccc}
\hline Parameters & Value & Parameters & Value \\
\hline Population & 50 & $\begin{array}{c}\text { Crossover } \\
\text { probability } \\
\text { Mutant }\end{array}$ & 0.8 \\
Iterations & 150 & \begin{tabular}{c} 
probability \\
\hline
\end{tabular} \\
\hline
\end{tabular}

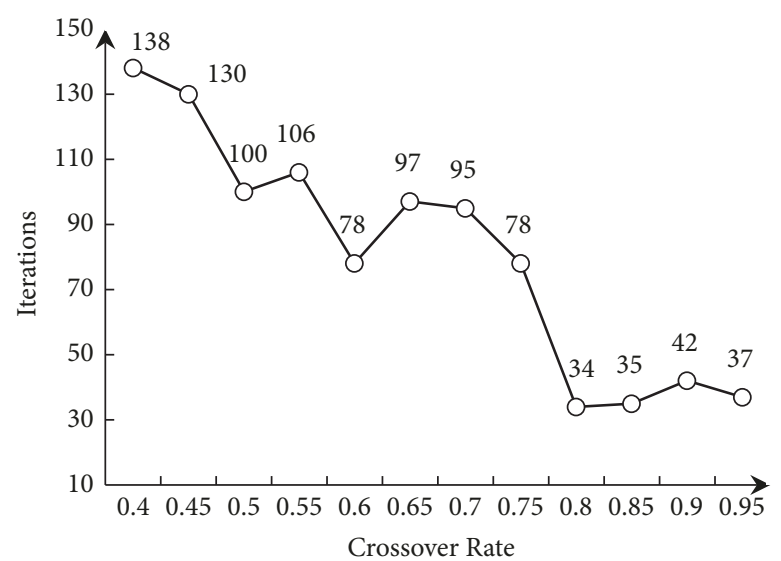

Figure 7: The relationship between the crossover rate and number of iterations.

iterations changes, iterations have little difference from each other and the final fitness value is invariable as Figures 7 and 8 show. Therefore, the final algorithm parameter values are shown in Table 7.

According to the case data, the maximum cross-section passenger flow appears at the BJ station in the downward direction, with 49333 people, so that the number of departure times during the optimization period is 20 pairs/h. As the downward direction of the cross-section of the passenger flow is much larger than the upward direction, it is designed to operate the express and local train mode in the down direction. And in this situation, the optimal result is different with the different proportion of the express/local train. Based on the OD in Table 5 and formula (11), the ratio is approximately 1:2. However, in order not to leave out all the plans, the paper takes $3: 1,2: 1,1: 1,1: 2,1: 3$ as alternatives.

The case is calculated and analyzed according to the algorithm parameter in Table 7 and fitness function set as

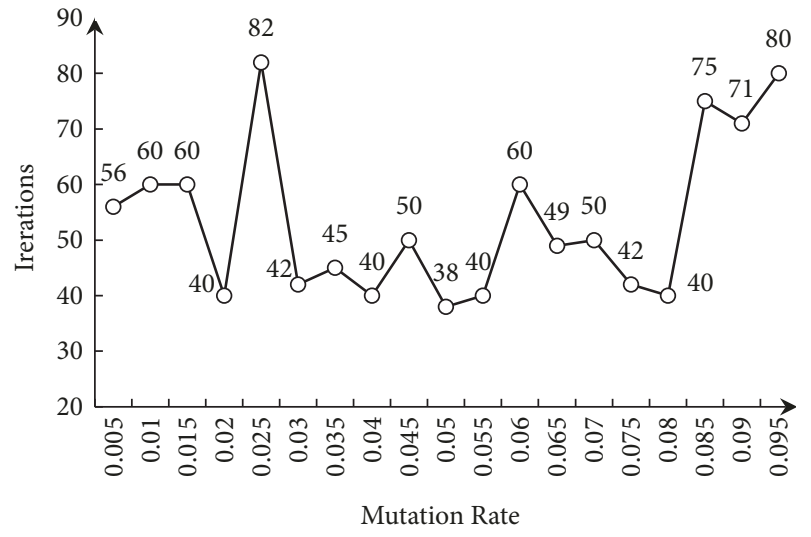

FIGURE 8: The relationship between the mutation rate and number of iterations.

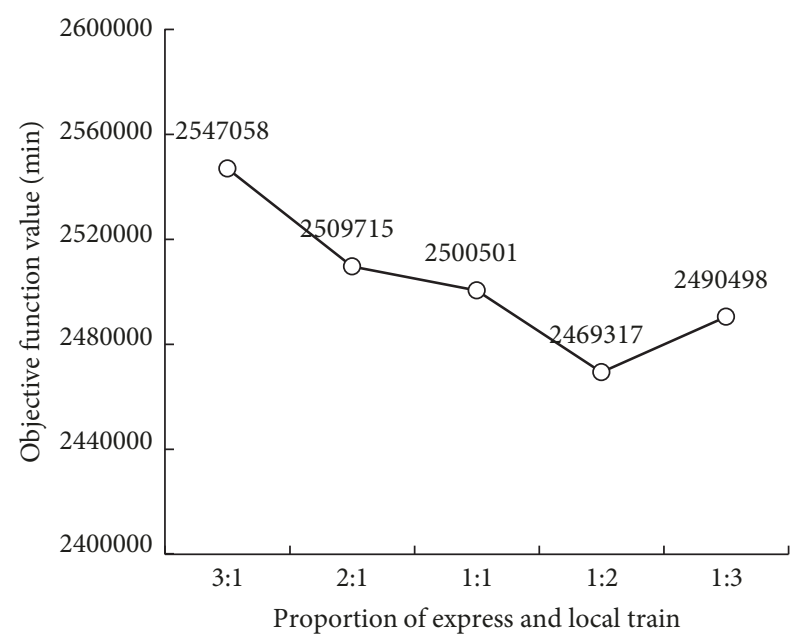

FIGURE 9: Variation of total travel time.

(15). Figure 9 shows the changing of travel time value. When the proportion is $1: 2$, that is to say, operating 6 express trains and 14 local trains, the passenger travel time is optimal. Corresponding express station stop scheme is shown in Table 8, in which 1 stands for stopping at station and 0 for no stopping, and express train overtakes the local at station ST and PSW without stopping. 
TABLE 8: The best express train stop scheme.

\begin{tabular}{lcccccccccccccccccc}
\hline Station & HZN & DH & NHL & ST & KZ & ZYK & PSW & SH & BL & NY & DY & AB & SL & SYL & BJ & QSH & HMG & GXB \\
Plan & 1 & 0 & 1 & 0 & 0 & 0 & 0 & 1 & 1 & 1 & 1 & 1 & 1 & 1 & 1 & 0 & 0 & 1 \\
\hline
\end{tabular}

TABLE 9: Total travel time comparison.

\begin{tabular}{lcccc}
\hline Compared content (unit) & General mode & Combination mode & Time benefit & Per capita benefit \\
\hline Total travel time $(\min )$ & 3638656 & 2469317 & 1169339 & 10.34 min \\
\hline
\end{tabular}

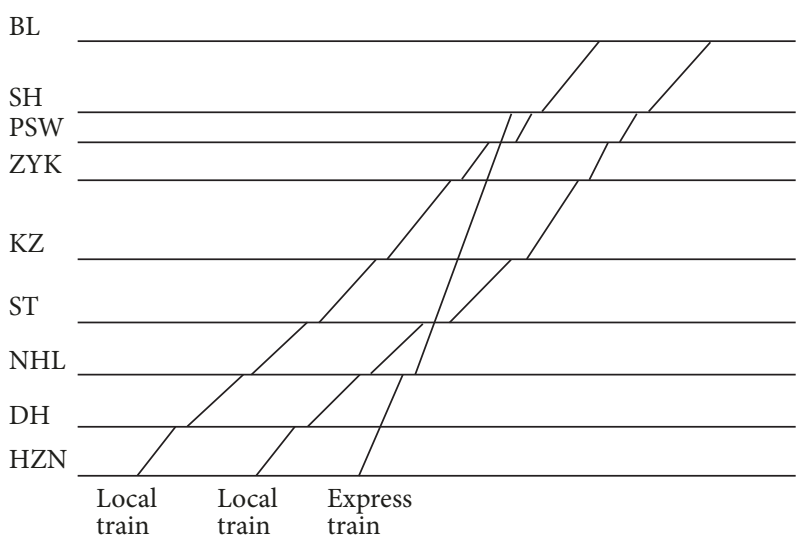

FIGURE 10: The sketch of train operation.

\subsection{Results Analysis}

4.3.1. Time Benefit Analysis. Compared with the general mode which only operates the local trains, the combination saves the passenger travel time with taking the express trains, whereas part of the passengers' time is increased because of slow trains. In the condition of the same train frequency, comparing the total travel time before and after the plan, like Table 9, we can see that in the specific passenger flow conditions, the time benefit is quite obvious.

4.3.2. Capacity Analysis. It has an effect on carrying capacity due to operating the express/local train. According to the parameters in the foregoing case, when the minimum headway is 120 s and the ratio of express and local train is 6:14 (roughly 1:2), where the capacity of general mode is 30 pairs/h, while in condition of the combination mode, the capacity depresses to 24 pairs/h.

From the stop scheme, we draw a train graph like Figure 10. With not considering the train turnaround temporarily, here we only draw the sketch of two sets of express/local train combination which run from the station HZN to the $\mathrm{BL}$, and the start order is the local train, local train, and the express train, respectively. In a triple of the combination, the first local train is crossed at station PSW, and the second is overtaken at ST without others.

4.3.3. Energy Consumption Comparison. The difference between the energy consumption of express trains and slow trains is mainly caused by the express train running directly at some stations without stopping and experiencing a kind of uniform speed at a longer distance in the interval. The train

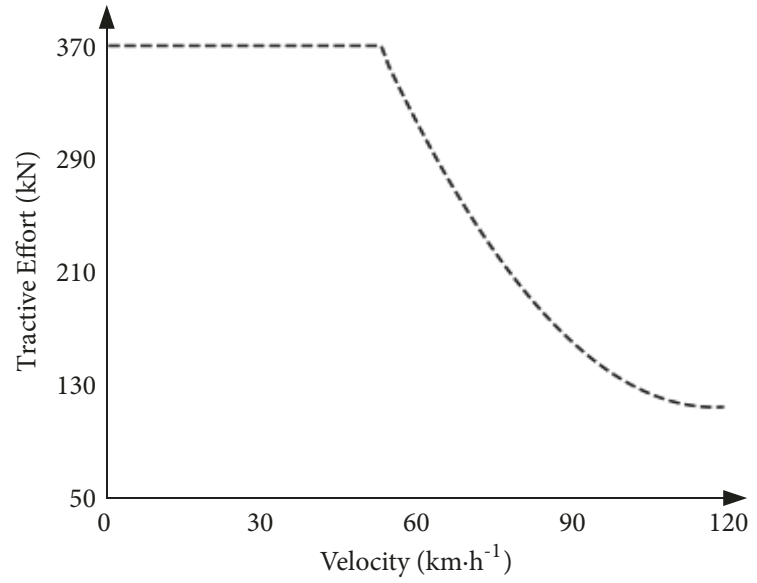

FIgURE 11: The sketch of traction curve.

traction curve, brake curve, and speed curve diagrammatic drawing are as shown in Figures 11, 12, and 13, respectively. Traction energy consumption and braking energy consumption are calculated by (4) and (5), and (6) represents the regenerative braking energy. Above all, the total consumption is as formula (3). In this case, there are three substations along the rail line. Under the above optimal stopping plan and the series calculation of train energy consumption, the results are compared in Table 10. It shows that the express/slow train mode has great advantages in energy saving and ensures the efficiency of the operating enterprises.

\section{Conclusion}

This paper studied the problem of the train stopping schedule in the condition of express and local train operation mode. With the analysis of the passengers' requirement to minimize the travel time, travel distance, and mainly the stations, the paper established a passenger train-choice model and used the entropy method to calculate the weight coefficient scientifically. On this basis, a 0-1 integer programming mathematical model aimed at minimizing the total travel time was set up, and the genetic algorithm was designed to solve the model. Finally, the algorithm result was insensitivity with the parameters. Besides, the travel time and energy consumption were both saved effectively through the case analysis, resulting in a considerable social benefits. However, the combination of express and local train operation reduced the line capacity, and the actual operation can change the ratio of express/local train to get relatively large capacity. 
TABLE 10: Train energy consumption comparison.

\begin{tabular}{lcccc}
\hline Compared content (unit) & General mode & Combination mode & benefit & Benefit rate \\
\hline Energy consumption $(\mathrm{KJ})$ & $1.41 \times 10^{8}$ & $1.19 \times 10^{8}$ & $2.26 \times 10^{7}$ & $16 \%$ \\
\hline
\end{tabular}

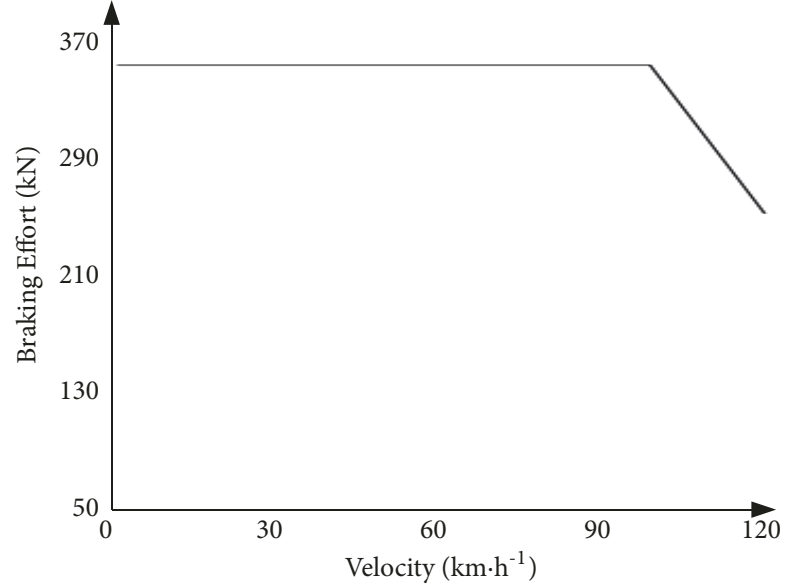

Figure 12: The sketch of brake curve.

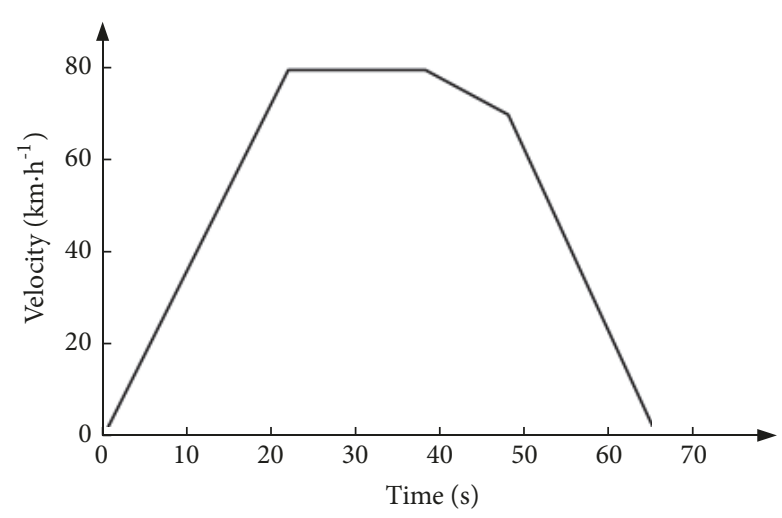

Figure 13: The sketch of speed curve.

\section{Conflicts of Interest}

The authors declare that they have no conflicts of interest regarding the publication of this paper.

\section{Acknowledgments}

This paper is supported by the Research Projects of the Social Science and Humanity on Young Fund of the Ministry of Education under Grant no. 15YJCZH108, the Research Projects of Natural Science Foundation of Guangdong Province under Grant no. 2015A030310341, and the Research Project of Shenzhen Technology University.

\section{References}

[1] Z. Rashedi, M. Mahmoud, S. Hasnine, and K. N. Habib, "On the factors affecting the choice of regional transit for commuting in Greater Toronto and Hamilton Area: Application of an advanced RP-SP choice model," Transportation Research Part A: Policy and Practice, vol. 105, pp. 1-13, 2017.

[2] C. Hirai, T. Kunimatsu, S. Kondou, N. Tomii, and M. Takaba, "Modelling and solving the train stop deployment planning problem," in Proceedings of the 12th IASTED International Conference on Artificial Intelligence and Soft Computing, ASC 2008, pp. 67-72, esp, September 2008.

[3] L. Wang and G. J. Wei, "Stopping Schedules of the Express /Local Train for Urban rail Transit Based on GASA Algorithm," Urban Mass Transit, vol. 18, no. 3, pp. 96-100, 2015.

[4] R. Tang and Y. Gao, "A Model of Customer Satisfaction-based for Express/Local Train Operation," Modern Urban Transit, vol. no. 5, pp. 59-64, 2015.

[5] E. Hassannayebi, S. H. Zegordi, M. R. Amin-Naseri, and M. Yaghini, "Train timetabling at rapid rail transit lines: a robust multi-objective stochastic programming approach," Operational Research, vol. 17, no. 2, pp. 435-477, 2017.

[6] J. H. Chun, R. M. Anderson, and D. Paik, "The S-train system: Synchronized express \& local trains for urban commuter rail systems," in Proceedings of the 14th IEEE International Intelligent Transportation Systems Conference, ITSC 2011, pp. 1586-1591, usa, October 2011.

[7] Y.-C. Lai, M.-C. Shih, and G.-H. Chen, "Development of efficient stop planning optimization process for high-speed rail systems," Journal of Advanced Transportation, vol. 50, no. 8, pp. 1802-1819, 2016.

[8] Y. Gao, L. Yang, and Z. Gao, "Energy consumption and travel time analysis for metro lines with express/local mode," Transportation Research Part D Transport \& Environment, 2016.

[9] D. Canca, E. Barrena, E. Algaba, and A. Zarzo, "Design and analysis of demand-adapted railway timetables," Journal of Advanced Transportation, vol. 48, no. 2, pp. 119-137, 2014.

[10] Q. Zhen and S. Jing, "Train rescheduling model with train delay and passenger impatience time in urban subway network," Journal of Advanced Transportation, vol. 50, no. 8, pp. 19902014, 2016.

[11] D. Di and D. Yang, "Passenger flow analysis model about express/slow train in urban rail transportation corridor," Tongji Daxue Xuebao/Journal of Tongji University, vol. 42, no. 1, pp. 7883, 2014.

[12] X. M. Zhao and Q. X. Sun, "Passenger Choice Behavior for Regional Rail Transit under Express/Local Operation with Overtaking," Journal of Transportation Systems Engineering and Information Technology, vol. 16, no. 5, pp. 104-109, 2016.

[13] R. Xu and X. Li, "Optimization of Routing Mode on Regional Express Rail," Urban Mass Transit, vol. 9, no. 5, pp. 36-39, 2006.

[14] J. Q. Liao, Research of Regional Rail Transit Express Train Plan, Beijing Jiaotong university, 2016.

[15] Q. Hu, "Study on Mixed-routing in Railway Transit for Disequilibrium Passenger Flow," Value Engineering, vol. 31, no. 32, pp. 81-83, 2012.

[16] Y. Zhu, B. Mao, Y. Bai, and S. Chen, "A bi-level model for singleline rail timetable design with consideration of demand and capacity," Transportation Research Part C: Emerging Technologies, vol. 85, pp. 211-233, 2017. 
[17] M. Y. Qu and S. M. Huang, "Study on express/local train plan of urban rail transit," Railway Transport and Economy, vol. 34, pp. 77-82, 2012.

[18] Q. Peng, W. Li, Y. Wang, Q. Zhong, and J. Sun, "Study on Operation Strategies for Metro Trains Under Regenerative Braking," Tiedao Xuebao/Journal of the China Railway Society, vol. 39, no. 3, pp. 7-13, 2017.

[19] K. Nomura and M. Miyatake, "Scheduling method for minimum energy consumption considering constraints of time intervals between local and express trains," in Proceedings of the 2016 IEEE International Conference on Intelligent Rail Transportation, ICIRT 2016, pp. 469-475, gbr, August 2016.

[20] X. M. Zhao, Q. X. Sun, Y. Ding, R. J. Shi, and Y. Chen, "Passenger choice behavior for regional rail transit under express/local operation with overtaking," Journal of Transportation Systems Engineering and Information Technology, vol. 16, no. 5, pp. 104109, 2016.

[21] Y. Wang, T. Tang, B. Ning, T. J. J. van den Boom, and B. De Schutter, "Passenger-demands-oriented train scheduling for an urban rail transit network," Transportation Research Part C: Emerging Technologies, vol. 60, pp. 1-23, 2015.

[22] X. Wang, H. Wang, and X. Zhang, "Stochastic seat allocation models for passenger rail transportation under customer choice," Transportation Research Part E: Logistics and Transportation Review, vol. 96, pp. 95-112, 2016.

[23] L. R. Huang, Research on operation organization of urban rail transit of express/local train, Southwest Jiaotong University, 2017.

[24] H. Niu and X. Zhou, "Optimizing urban rail timetable under time-dependent demand and oversaturated conditions," Transportation Research Part C: Emerging Technologies, vol. 36, pp. 212-230, 2013.

[25] W. Li, R. Xu, and W. Zhu, "Multi-line cooperation method for passenger flow disposal in metro transfer station under train delay," Tongji Daxue Xuebao/Journal of Tongji University, vol. 43, no. 2, pp. 239-244, 2015. 


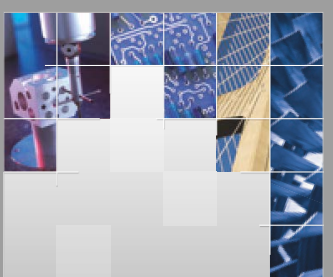

\section{Enfincering}
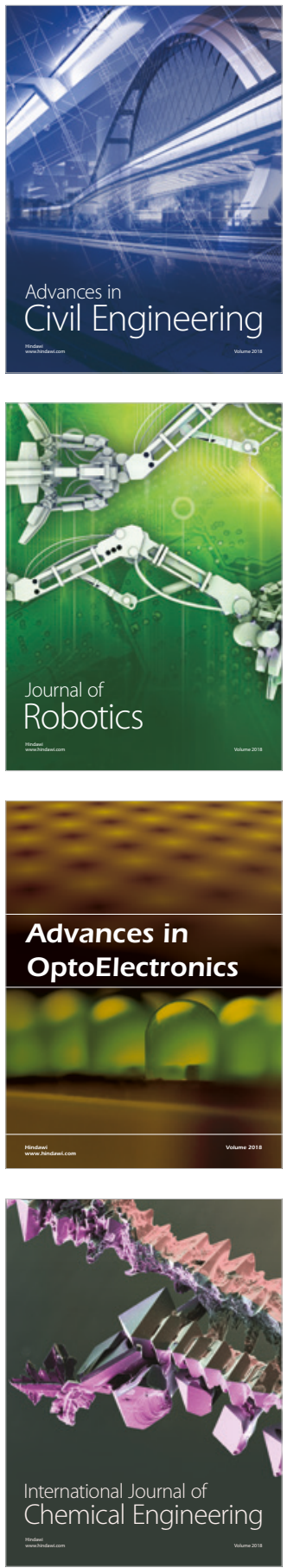

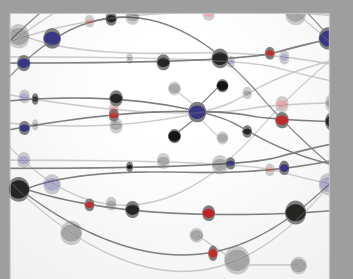

\section{Rotating \\ Machinery}

The Scientific World Journal

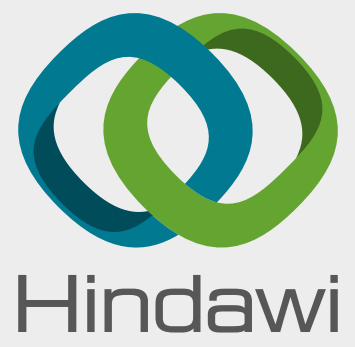

Submit your manuscripts at

www.hindawi.com
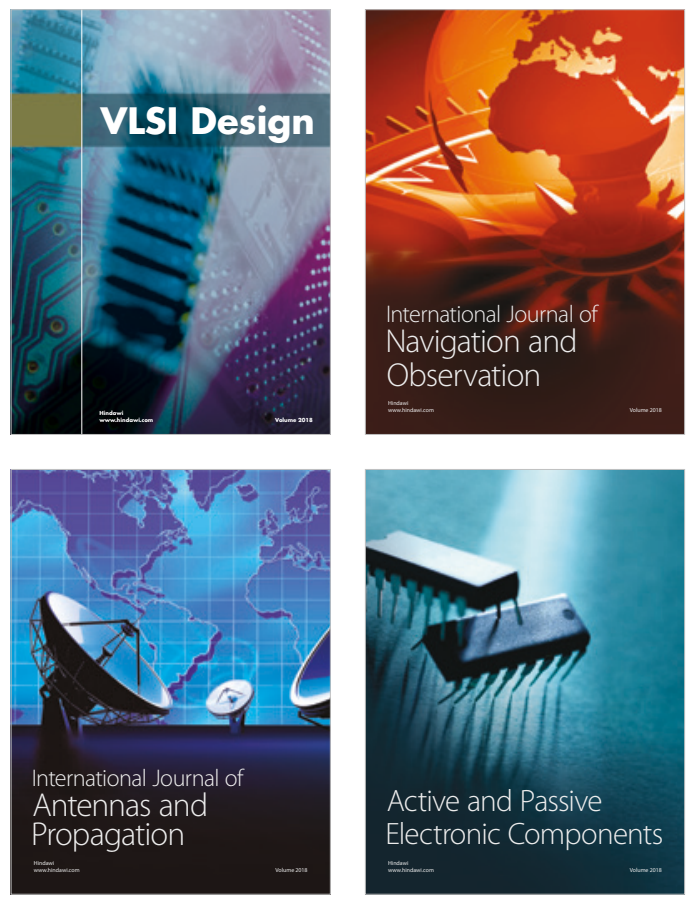
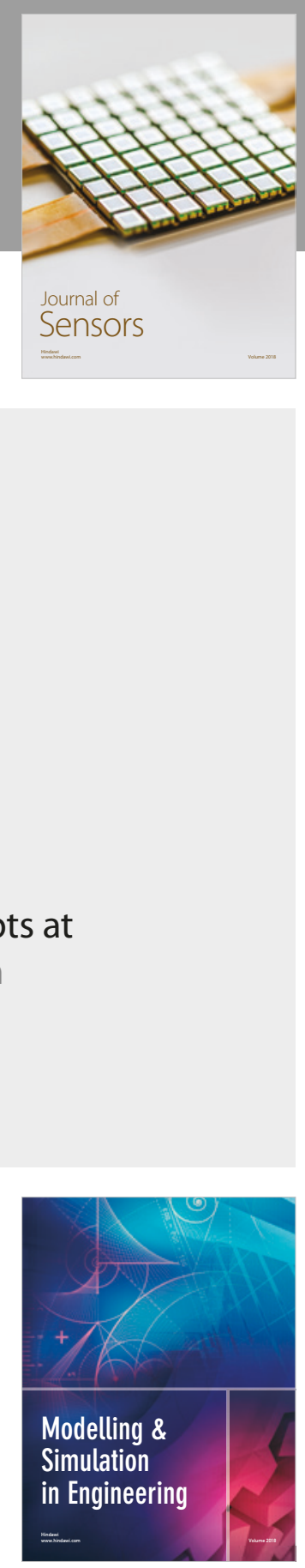

\section{Advances \\ Multimedia}
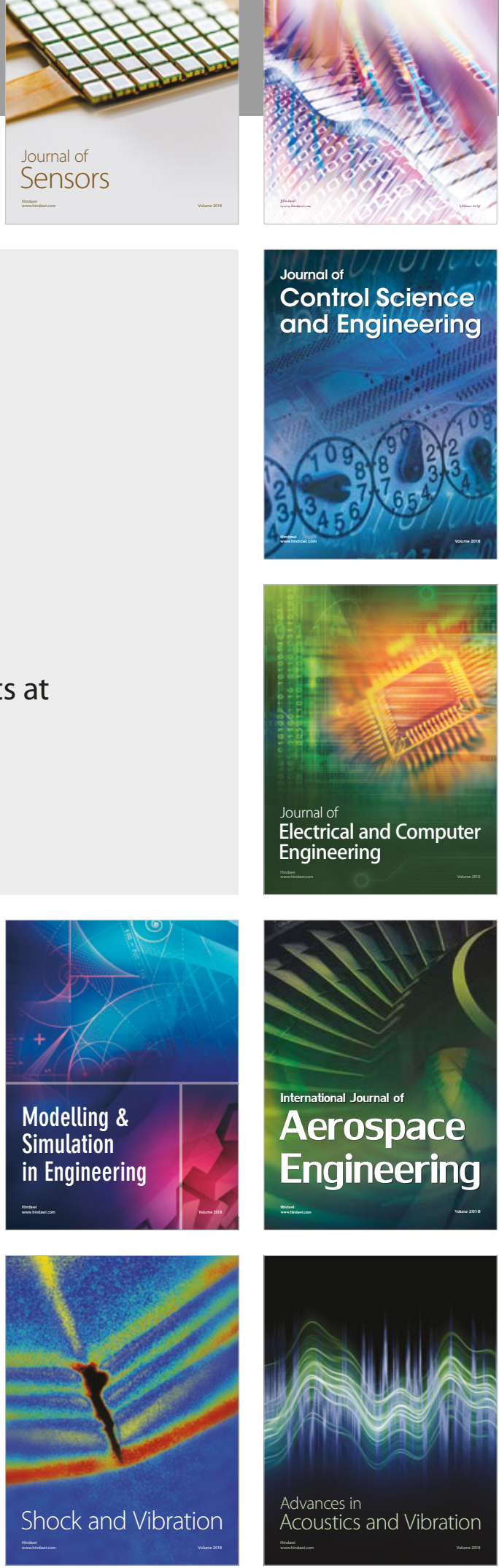